\title{
O desenvolvimento do senso analítico no processo de ensino e aprendizagem na Educação Ambiental
}

\author{
El desarrollo del análisis analítico no se procesa ni se aprende en la
}

\author{
educación ambiental
}

The development of the analytical sense in the teaching and learning

process in Environmental Education

\author{
Ronualdo Marques ${ }^{1}$ \\ Claudia Regina Xavier ${ }^{2}$
}

\begin{abstract}
Resumo
A Educação Ambiental no processo de ensino e aprendizagem interfere diretamente em nossas vidas e discuti-la possibilita interação e inter-relação para aproximar teoria à prática a partir de reflexões e discussões para que este saber contribua com a mudança de comportamento dos indivíduos em sua relação com o Meio Ambiente. Este estudo exibe uma discussão sobre as inferências levantadas na aplicação de uma Sequência Didática sobre a Pegada Ecológica do Lixo para a promoção da Educação Ambiental, buscando identificar e analisar o desenvolvimento do senso analítico de estudantes de uma turma de $6^{\circ}$ ano do Ensino Fundamental de CuritibaPR. Observou-se na aplicação da Sequência Didática que o uso de argumentos não é uma capacidade inata e só se adquire pela prática, bem como a importância da relação dialógica e a importância do discurso na aquisição do conhecimento científico. Dessa forma conclui-se a presença de um ensino explícito da argumentação melhora o envolvimento dos estudantes tanto quanto ao conhecimento como a sua capacidade de tomada de decisões, manifestando o senso analítico dos alunos, visto que o desenvolvimento de ações integradas e participativas potencializa as discussões que emergem das relações entre os seres humanos, a sociedade e a natureza.
\end{abstract}

Palavras-Chave: Senso Analítico; Pegada Ecológica do Lixo; Ensino e aprendizagem; Educação Ambiental.

\section{Resumen}

La Educación Ambiental en el proceso de enseñanza y aprendizaje interfiere directamente en nuestras vidas y discute posibilita interacción e interrelación para aproximar teoría a la práctica a partir de reflexiones y discusiones para que este saber contribuya con el cambio de comportamiento de los individuos en su relación con el Medio Ambiente. Este estudio muestra una discusión sobre las inferencias planteadas en la aplicación de una Secuencia Didáctica sobre la huella ecológica de la basura para la promoción de la educación ambiental,

\footnotetext{
${ }^{1}$ Mestre em Ensino de Ciências no Programa de Mestrado em Educação Científica e Tecnológica pela Universidade Universidade Tecnológica Federal do Paraná (PPGFECT-UTFPR); especialização em Educação Especial pela Faculdades Integradas do Vale do Ivaí (UNIVALE); especialização em Educação e Gestão Ambiental pela Faculdades Integradas do Vale do Ivaí (UNIVALE); especialização em Gestão Pública Municipal pela UTFPR - Universidade Tecnológica Federal do Paraná (UTFPR); especialização em Filosofia Contemporânea pela Faculdade de Administração, Ciências, Educação e Letras (FACEL). Graduando em Pedagogia no Centro Universitário Internacional (UNINTER). Graduação em CIÊNCIAS BIOLÓGICAS pela Universidade Estadual do Centro-Oeste (UNICENTRO). E-mail: ronualdo.marques@gmail.com.

${ }^{2}$ Profa. Dra. no Programa de Mestrado de Formação Científica, Educacional e Tecnológica - FCET/UTFPR. Possui graduação em Licenciatura e Bacharelado em Química pela Universidade Federal do Paraná (1996) e mestrado em Química pela Universidade Federal do Paraná (1998). Participou em Treinamento Avançado em Instrumentos de Gestão Ambiental em Hamburgo- Alemanha (2001) e posteriormente se titulou doutora em Ciências Ambientais pela Universidade de Concepción- Chile (2006). Atualmente é Professora Titular da Universidade Tecnológica Federal do Paraná- UTFPR. E-mail: cxavier.utfpr@gmail.com.
} 
buscando identificar y analizar el desarrollo del sentido analítico de estudiantes de una clase de $6^{\circ}$ año de la Enseñanza Fundamental de Curitiba -PR. Se observó en la aplicación de la Secuencia Didáctica que el uso de argumentos no es una capacidad innata y sólo se adquiere por la práctica, así como la importancia de la relación dialógica y la importancia del discurso en la adquisición del conocimiento científico. De esta forma se concluye la presencia de una enseñanza explícita de la argumentación mejora la participación de los estudiantes tanto en cuanto al conocimiento como su capacidad de toma de decisiones, manifestando el sentido analítico de los alumnos, ya que el desarrollo de acciones integradas y participativas potencializa las discusiones que emergen de las relaciones entre los seres humanos, la sociedad y la naturaleza.

Palabras claves: Sentido Analítico; Huella Ecológica de la basura; Enseñanza y aprendizaje; Educación ambiental.

\begin{abstract}
Environmental Education in the process of teaching and learning interferes directly in our lives and discussing it enables interaction and interrelation to bring theory to practice from reflections and discussions so that this knowledge contributes to the behavioral change of individuals in their relationship with the Environment. This study presents a discussion about the inferences raised in the application of a Didactic Sequence on the Garbage Ecological Footprint for the promotion of Environmental Education, aiming to identify and analyze the development of the analytical sense of students of a 6th grade class of the Elementary School of Curitiba -PR. It was observed in the application of the Didactic Sequence that the use of arguments is not an innate capacity and is only acquired by practice, as well as the importance of the dialogic relation and the importance of the discourse in the acquisition of scientific knowledge. In this way, the presence of an explicit teaching of argumentation improves students' involvement as much as knowledge as their decision-making capacity, manifesting the analytical sense of the students, since the development of integrated and participative actions potentiates the discussions which emerge from the relations between human beings, society and nature.
\end{abstract}

Keywords: Analytical Sense; Ecological Garbage Footprint; Teaching and learning; Environmental education.

\title{
1. Introdução
}

Ao longo dos séculos, a humanidade desvendou, conheceu, dominou e modificou a natureza para melhor aproveitá-la. Estabeleceu outras formas de vida, e, por conseguinte, novas necessidades foram surgindo e os homens foram criando novas técnicas para suprirem essas necessidades, muitas delas decorrentes do consumo e da produção (SANTOS; FARIA, 2004).

O trabalho educacional voltara para a Educação Ambiental é componente dessas medidas das mais essenciais, necessárias e de caráter emergencial, pois sabe-se que a maior parte dos desequilíbrios ecológicos está relacionada a condutas humanas inadequadas impulsionadas por apelos consumistas - frutos da sociedade capitalista - que geram desperdício, e ao uso descontrolado dos bens da natureza, a saber, os solos, as águas e as florestas (CARVALHO, 2006).

Sendo assim, enfrentamos um momento de mudança de paradigma com relação à concepção de uso de recursos Naturais e convivência com o Meio Ambiente. A crise que vivenciamos pode ser considerada como uma crise de valores, o que tem gerado problemas sociais e ambientais das mais variadas proporções (SANTOS; FARIA, 2004). 
A Educação Ambiental é conteúdo e aprendizado, é motivo e motivação, é parâmetro e norma. Vai além dos conteúdos pedagógicos, interage com o ser humano de forma que a troca seja uma retroalimentação positiva para ambos. Educadores ambientais são pessoas apaixonadas pelo que fazem. E, para que o respeito seja o primeiro sentimento motivador das ações, é preciso que a escola mude suas regras para que a Educação Ambiental aconteça de uma forma mais humana (CARVALHO, 2006). Assim se faz necessário uma educação que possibilite uma visão integral da relação homem, sociedade e natureza, ou seja, uma “educação holística , uma educação que estimule o senso crítico, que estimule métodos e traga à tona discussões, que desperte os interesses dos alunos" (CHALITA, 2002).

Quando consideramos decisiva uma atitude consciente na ação histórica, lembramos Damke "se a conscientização indica o processo de inserção crítica dos seres humanos na ação transformadora da realidade, ligam-se a ela duas tarefas fundamentais: desmistificar a realidade e agir sobre ela para modificá-la" (DAMKE, 1995, p. 97).

Para Guedes (2006, p. 87), “[...] os sistemas educacionais com fortes tendências pedagógicas liberais tradicionais não compreendem ou não têm aceitado a Educação Ambiental como parte integrante do currículo e da vida escolar, impossibilitando, desta forma, a consolidação desta". Para Morin (apud GUEDES, 2006, p. 89) "se define como a articulação entre as disciplinas levando à articulação dos saberes”. Na visão de Guimarães (1995), o Ensino Médio, por exemplo, tem visado apenas o vestibular e se esquece da formação de cidadãos que pensem de forma crítica e que vejam o mundo e o próximo não como um adversário, mas como um cidadão.

O conhecimento tem mais valor quando construído coletivamente porque repartimos o que sabemos e aprendemos com o que os outros repartem conosco. É com esta construção coletiva que o ensino deve se preocupar mais (YUS, 2002).

A Educação Ambiental obedece a um processo civilizatório de mudanças desde sua criação, como não poderia deixar de ser, pois é educação. Sendo assim, ela incorpora no seu discurso tendências atual cada vez mais diversificada, pois, temos que a escola atual almeja oferecer uma educação compromissada com os múltiplos aspectos da vida humana, os quais envolvem não só os problemas socioeconômicos, mas também os fatores éticos e afetivos, bem com o os anseios existenciais quanto ao sentido da vida. Esse compromisso se torna evidente na "Carta de Transdisciplinaridade" (Freitas et al., 2000), cujo conteúdo anuncia um novo modo de conhecimento e, consequentemente, de educação. Trata-se, segundo, de "aprender a conhecer", o que significa ser capaz de "estabelecer pontes - entre os diferentes 
saberes, entre estes saberes e seus significados para nossa vida cotidiana, entre estes saberes e significados e nossas capacidades interiores" (NICOLESCU, 2000, p. 150).

É necessário que hoje o cidadão tenha uma concepção da necessidade e importância que a Educação ambiental tem como uma ferramenta estratégica na preservação e conservação do meio ambiente como também, na luta de seus direitos. Para promover a Educação Ambiental e o senso analítico e necessário que estimule o desenvolvimento de discussões a partir do diálogo que permita ao aluno criar elementos para argumentação a partir da sua capacidade analítica e efetuar bons julgamentos a partir de fatos concretos ou evidências.

Toulmin (1958) define argumento como sendo uma afirmativa acompanhada por seis componentes e suas relações,

\footnotetext{
- Dados: evidências que suportam uma afirmativa. • Conclusão: afirmativa cujo mérito deverá ser estabelecido. • Garantia: afirmativa que justifica as conexões entre dados e conclusão. • Apoio: afirmativa que justifica a garantia. • Qualificador modal: elemento que qualifica a conclusão em função da ponderação entre os elementos de justificativa e de refutação. • Refutação: especifica em que condições a garantia não é válida para dar suporte à conclusão (TOULMIN, 1958, p. 148).
}

Assim, é necessária uma prática sistemática de diálogo analítico, onde o estudante vai adquirindo senso crítico ao praticar, no diálogo, o exercício reflexivo de aprender a perceber inconsistências em suas afirmações, como redundância, contradição, ambiguidade, generalização, simplificação, entre outros. Esses problemas estimulam intolerâncias e individualismos através de uma percepção fantasiosa da realidade promovida por equívocos na elaboração dos argumentos enquanto mecanismo de percepção da verdade (BAGGINI; FOSL, 2008, p. 31).

A argumentação pode ser pensada de três formas diferentes: retórica, dialética e lógica (WENZEL, 1990). O estudo da retórica, da dialética e da lógica teve origem na Grécia Antiga, sendo que o trabalho de Aristóteles é o que mais se destaca.

A síntese de Wenzel (1990) nos possibilita entender a principal diferença entre essas formas de pensar na argumentação. Segundo a perspectiva retórica, um bom argumento consiste da produção de discurso (escrito ou falado) que efetivamente auxilia membros de um grupo social a resolver problemas e tomar decisões. De forma geral, o propósito principal da retórica é a persuasão, empregada na escolha entre alternativas. Na perspectiva dialética, um bom argumento consiste da organização sistemática de uma interação (por exemplo, debate e discussão) com vistas à produção das melhores decisões possíveis. Finalmente, segundo a 
perspectiva lógica, um bom argumento é constituído de afirmativas sustentadas por evidências e razões suficientes e relevantes. Nesse sentido, Wenzel (1990) afirma que a retórica está associada ao processo de produção de argumentos, a dialética ao procedimento envolvido, e a lógica ao argumento enquanto produto. Segundo Wenzel (1990), as teorias que foram desenvolvidas para cada perspectiva se relacionam com os interesses para os quais cada uma se dirige.

A partir dessa concepção teórica surge a indagação que precisam ser analisadas para compreender como acontece a elaboração dos elementos do senso analítico dos estudantes diante dos temas da Educação Ambiental, ou seja, Como é possível identificar elementos que evidenciem o desenvolvimento do senso analítico dos alunos do $6^{\circ}$ ano do Ensino Fundamental através da Educação Ambiental?

\section{Elementos para a formação do senso analítico}

O senso analítico está ligado à capacidade de analisar e ver o detalhe e encontrar soluções seja com base em números ou em percepções. A capacidade de análise está atrelada a nossa capacidade de enxergar o mundo com outros olhos. A verdade é que vivemos em dois mundos, um das ideias e outro da realidade. Nossa mente é capaz de lidar com estas duas realidades e uma modifica radicalmente a outra. Esta relação que desenvolve entre as ideias e a realidade é o que possibilita o desenvolvimento do senso analítico.

Existem cinco passos para o desenvolvimento ou para uma pessoa se tornar um analista, ou seja, alguém capaz de conectar as ideias à realidade; são eles: "a) entender como a nossa mente funciona e quebrar o processo automático; b) entender a organização dos dados; c) entender o que é informação e como desenvolver a capacidade de análise; d) estruturar a informação para facilitar a tomada de decisão; e) incorporar a cultura da tomada de decisão com base em dado" (MARQUES, 2018, p. 54).

Mortimer e Santos (2001, p. 99) apresenta um detalhamento sobre passos para o processo da estruturação da informação, solução de problemas e a tomada de decisão que está diretamente relacionada ao desenvolvimento do senso analítico. Segundo ele, os currículos deveriam ser estruturados de forma a propiciar condições para que os alunos desenvolvam os passos da tomada de decisão, os quais consistem em:

1. Reconhecimento da existência de um problema;

2. Compreensão da essência factual do conhecimento e conceitos envolvidos; 
3. Apreciação do significado e sentido das soluções alternativas;

4. Processamento para solução do problema: a) Seleção de dados e informações relevantes; b) Análise dos dados pela sua racionalidade, confiabilidade e validade; c) Avaliação da dependência das fontes de informações usada e seus graus de preconceito; d) Planejamento de estratégias apropriadas para mais adiante negociar com os problemas;

5. Esclarecimento dos valores de cada um e estabelecimento de um julgamento de valor;

6. Processamento para a tomada de decisão: a) Escolhas racionais entre alternativas disponíveis ou geração de novas opções; b) Tomada de decisão;

7. Ação de acordo com a decisão tomada;

8. Tomada de responsabilidade (ZOLLER, 1993, p. 97).

Assim temos que a formação das capacidades de Inteligência Analítica permite que as pessoas passem a tomar decisões mais bem informadas (HODGKINSON; STARBUCK, 2008; LAVALLE et al., 2011; COMUZZI; PATEL, 2016). A qualidade das informações é definida pelos atributos de: acessibilidade; quantidade apropriada; credibilidade; completude; concisão; consistência; usabilidade; fiabilidade; interpretabilidade; objetividade; relevância; reputação; segurança; tempestividade; compreensividade; e, valor agregado (PIPINO; LEE; WANG, 2002).

Apesar da tomada de decisão requerer um máximo de informação, para o bom exercício do processo decisório, não basta apenas uma grande quantidade: é preciso atentar-se para a qualidade. Para fundamentar decisões, a informação deve ser confiável, isto é, correta, fidedigna, segura, disponível em tempo hábil, e de forma controlada. A informação deve assumir o papel de redutora de incerteza e fonte de segurança (BRAGA, 2000; MANGUEIRA; ALVES, 2014).

Quanto mais qualificadas as informações, mais inteligentes serão as ações, e maior será a redução do grau de incertezas (EVANS, 2012; BANERJEE; BANDYOPADHYAY; ACHARYA, 2013).

Assim, a tomada de decisão elemento para a formação do senso analítico, são encontrados na literatura algumas características da capacidade analítica que é definida por Amaral (2006) como a capacidade de avaliar e interpretar sistematicamente os dados, a fim de identificar fatos relevantes, insights e relacionamentos-chave, para o estabelecimento de conclusões úteis à tomada de decisão, como mostrado no Quadro 1 a seguir: 
RELACult - Revista Latino-Americana de Estudos em Cultura e Sociedade

Revista Latinoamericana de Estudios en Cultura y Sociedad | Latin American Journal of Studies in Culture and Society V. 05, no 02, maio-ago., 2019, artigo no 1393 | claec.org/relacult |e-ISSN: 2525-7870

\begin{tabular}{|c|c|c|}
\hline Conhecimento & Habilidades & Atitude \\
\hline $\begin{array}{l}\text { - Organização de } \\
\text { informações }\end{array}$ & $\begin{array}{l}\text { - Aprender com as experiências; } \\
\text { - Capacidade de síntese; } \\
\text { - Discernimento; } \\
\text { - Extrair dados relevantes; } \\
\text { - Gerar explicações consistentes dos fatos; } \\
\text { - Gerar recomendações de acordo com a } \\
\text { análise; } \\
\text { - Interpretação de dados-Intuição } \\
\text { - Julgamento } \\
\text {-Lidar com ambiguidades, conflitos e dados } \\
\text { incompletos; } \\
\text { - Organizar informações; } \\
\text { - Pensamento analítico; } \\
\text { - Perspicácia; } \\
\text { - Raciocínio estratégico; } \\
\text { - Raciocínio lógico; } \\
\text { - Resolução de problemas; } \\
\text { - Visão de futuro; } \\
\text { - Visão global. }\end{array}$ & $\begin{array}{l}\text { - Agilidade; } \\
\text { - Confiabilidade; } \\
\text { - Estar constantemente atento às informações; } \\
\text { - Criatividade } \\
\text { - Curiosidade } \\
\text { - Discrição } \\
\text { - Meticulosidade } \\
\text { - Observação } \\
\text { - Organização } \\
\text { - Percepção } \\
\text { - Segurança; } \\
\text { - Seriedade; }\end{array}$ \\
\hline
\end{tabular}

De acordo com o estudo de Amaral (2006) o desenvolvimento do senso analítico está diretamente ligado à capacidade analítica e é uma característica que diz respeito às habilidades de analisar dados, nem sempre diretamente relacionados entre si, e a partir desta análise produzir informação de valor ou conhecimento. Também diz respeito à capacidade de receber informações de várias fontes e organizar esta informação de forma racional. Como apresentados no Quadro 01 sobre a capacidade analítica, baseado no conhecimento, habilidades e atitudes.

Considerando que o processo de ensino e aprendizagem resulta da atividade ou técnica em que resulta em conhecimento sendo adquirido e aliados a este processo têm que o desenvolvimento do senso analítico contribui a partir da cognição que é definida como o ato ou processo de conhecer em que alguns processos cognitivos precisam ocorrer para produzir conhecimento. A cognição aborda modelos mentais e crenças, ou, ainda, estruturas de conhecimento (EGGERS; KAPLAN, 2013), isto é, de emoções e processos mentais frente à vastidão e complexidade de informações que os estudantes processam, fundamentadas em "estruturas de conhecimento" para representar seus modelos mentais de informação (WALSH, 1995). Esse conceito é aprofundado no estudo de Helfat e Peteraf (2015), no qual são identificados os tipos específicos de capacidades cognitivas que podem sustentar as capacidades dinâmicas para detecção, apreensão e reconfiguração, explicando o seu potencial impacto na mudança estratégica.

A cognição molda a maneira pela qual os estudantes processam, interpretam e geram informações; as percepções sobre a realidade têm uma influência sobre as decisões tomadas 
(BECK; WIERSEMA, 2013). Os que possuem processos associativos mentais superiores podem evitar riscos, e têm maior sucesso na identificação de oportunidades estratégicas promissoras (GAVETTI, 2012).

Para explorar os fundamentos das capacidades cognitivas, parte-se para a revisão conceitual das capacidades identificadas no modelo de Helfat e Peteraf (2015), como percepção, atenção, raciocínio, resolução de problemas, linguagem e comunicação, e cognição social.

\section{- $\quad$ Percepção}

É distinguida a partir da sensação, e se refere à experiência subjetiva ou sentimento que ocorre quando os receptores sensoriais são ativados; é o processo ou resultado de se tornar consciente de objetos, relacionamentos e eventos, por meio dos sentidos, o que inclui atividades como reconhecer, observar e discriminar. Essas atividades permitem que os organismos se organizem e interpretem os estímulos (APA, 2010), e as experiências anteriores e conhecimentos adquiridos possam moldar novas percepções (HELFAT; PETERAF, 2015). A percepção é de extrema importância, porque o comportamento das pessoas é baseado na interpretação que elas fazem da realidade. À medida que o indivíduo adquire novas informações, sua percepção se altera.

A percepção é o processo sensorial de extração de informação do meio ambiente, o qual permite atribuir significado às coisas e objetos, isto é, tornar-se consciente dos objetos e das relações no mundo circundante; percebe-se a partir do que se sabe, ou seja: a percepção está diretamente relacionada ao conhecimento (MATIAS; GRECO, 2010).

\section{- $\quad$ Atenção}

Diariamente todos são bombardeados com uma grande quantidade de informações que, muitas vezes, excedem sua capacidade de desenvolvimento cognitivo (SIMON, 1991). Uma forma de administrar essa sobrecarga cognitiva é através do processo de atenção seletiva, que concentra os aspectos considerados mais relevantes, ignorando, seletivamente, os demais. É importante desenvolver representações subjetivas de seu ambiente, que lhes proporcionam uma lente através da qual visualizam os eventos e as atividades presentes e tomam decisões (NADKARNI; BARR, 2008).

É um estado intenso e seletivo da percepção, pois, quando se recebem vários estímulos sensoriais do ambiente, é preciso interpretá-los e compreendê-los. Faz o papel de filtro, viabilizando que apenas uma parcela limitada da quantidade desses estímulos sensoriais 
torne-se evidente na percepção. A atenção, apoiada na experiência, focaliza o que se deseja perceber (MATIAS; GRECO, 2010).

Assim, o foco de atenção torna-se importante, pois capacita os gestores com um filtro cognitivo, por meio do qual podem focalizar sua atenção de modo dirigido, a fim de identificar problemas, riscos e oportunidades presentes no ambiente de negócios.

\section{- Raciocínio e Resolução de Problemas}

São as faculdades mentais que permite-nos raciocinar, planejar, resolver problemas, pensar de maneira abstrata, compreender ideias complexas e aprender. Manifestam-se através do processo de seleção de uma estratégia para solução de determinado problema, especialmente ao se defrontar com situações novas, momentos nos quais o indivíduo mobiliza conhecimentos e habilidades existentes. Estão associadas à capacidade humana de se adaptar às situações adversas do meio onde se encontra (MATIAS; GRECO, 2010).

Portanto, "Raciocínio" se refere à avaliação de informações, argumentos e crenças para chegar a uma conclusão, ou usar informações para determinar se uma conclusão é razoável ou válida. "Resolução de Problemas" é encontrar uma maneira de contornar um obstáculo, para alcançar um objetivo.

\section{- $\quad$ Linguagem e Comunicação}

É todo e qualquer sistema de representação e comunicação de ideias. A reconfiguração é influenciada pela capacidade em persuadir os outros para compreender novas iniciativas diante uma situação, já que a linguagem pode ser usada para comunicar os objetivos e promover o alinhamento dentro um espaço comum. O modo como eles comunicam uma visão pode inspirar, incentivar e impulsionar o crescimento do coletivo; tanto a linguagem quanto as expressões não verbais afetam a forma como as pessoas reagem às mudanças. Desse modo, devem aprimorar suas habilidades narrativas como um meio de motivar e mobilizar-se em torno de uma nova estratégica ou ação (HELFAT; PETERAF, 2015).

\section{- Cognição Social}

Para Teece et al., (1994), as condições de mudança, muitas vezes, requerem uma atividade cooperativa em um grupo. O conceito de cognição social trata das habilidades de induzir a cooperação entre os membros de um grupo e influenciar o comportamento social que envolve as relações e interações entre as pessoas; também inclui a capacidade de entender o ponto de vista do outro (empatia) e, portanto, permite que o professor influencie os demais 
membros do grupo, a fim de promover a reconfiguração estratégica, quer seja por fomentar a cooperação, propiciar melhores incentivos à mudança, ou enquadrar suas comunicações de forma mais eficaz (HELFAT; PETERAF, 2015).

\section{Metodologia}

A pesquisa foi aplicada na perspectiva da Pesquisa Participante que segundo Esteban (2010) compreende como um processo compartilhado de desconstrução, construção e reconstrução de conhecimentos em uma ação transformadora e emancipadora. Além disso, o professor busca entender como os estudantes compreendem suas próprias situações e como constroem suas realidades, combinando ao mesmo tempo a participação ativa dos estudantes, as conversas informais e as análises das atividades desenvolvidas.

A pesquisa foi realizada no Colégio Estadual Júlia Wanderlei da Rede Pública Estadual do Paraná no Município de Curitiba. Participaram deste estudo 20 estudantes do $6^{\circ}$ ano do Ensino Fundamental, sendo 11 meninos (55\%) e 9 meninas (45\%), com idade entre 11 e 12 anos, denominados pelas siglas "A" (Aluno A01, A02, etc.) estando em consonância com os documentos Termo de Assentimento Livre esclarecido para menores de 18 anos - TALE, Termo de Consentimento livre e esclarecido - TCLE, respeitando a privacidade e o sigilo do educando conforme termo de aprovação do Comitê de ética nº 60796516.0000.5547.

Foi proposta uma Sequência Didática investigativa sobre a Pegada Ecológica do Lixo organizada com diferentes instrumentos, tais como aulas expositivas, ilustrativas, demonstrativas, dialogadas, práticas e visita a campo, para o estudo de temas que contemplassem o lixo como tema gerador de conhecimento de forma contextualizada com atividades teóricas, dinâmicas, vídeos, músicas, desenhos, charges, jogos, propagandas, brincadeiras; além de práticas no pátio da escola, horta escolar e ruas no entorno da escola que pudesse ser interessante para o aluno. Estas atividades têm se mostrado relevantes pela sua capacidade de motivar o aluno a participar espontaneamente da aula, por privilegiar o trabalho em grupo, a relação dialógica entre professores e alunos, além de promover a cooperação, a socialização e instigar a curiosidade infantil (PEDROSO, 2009).

Para coleta de dados foi utilizado um questionário que foi validado por professores do Programa de Pós-Graduação em Formação Científica, Educacional e Tecnológica-FCET e aprovado no marco do projeto do Comitê de Ética e Pesquisa - CEP.

Primeiramente foi utilizado apresentado a Sequência Didática sobre Educação Ambiental com enfoque na Pegada Ecológica do Lixo. Dentre as temáticas na Sequência Didática estavam: 
Resíduos Sólidos, Classificação dos tipos de lixo, Tipos de Lixeira, Reutilização, Política dos 3R's, Reciclagem, Coleta Seletiva, Destino final do lixo, Lixo orgânico, Compostagem.

Na aplicação da Sequência Didática sobre a Pegada Ecológica do lixo - PEL, inicialmente foram realizadas rodas de conversa para perceber os conhecimentos prévios e posteriormente perceber a construção da Alfabetização Científica, confrontando diferentes opiniões e novos posicionamentos, a partir das ferramentas disponíveis nas aulas teóricas e práticas estimulando-os, assim, à criatividade e ao "saber ouvir", dando oportunidade de expressarem suas opiniões, dúvidas, anseios. Isso possibilitou além da exposição de suas vivências e experiências com a temática do lixo promovendo a compreensão de ações e atitudes a fim de possibilitar reflexões, envolvimento, sensibilização e mudança de atitude para o cuidado com o Meio Ambiente.

As aulas mediadas com rodas de conversa (MEC, 2008), onde o professor media o diálogo dos alunos e vai complementando as conexões e questionando inconsistências nas afirmações que surgem. A roda de conversa "apresenta-se como um rico instrumento para ser utilizado como prática metodológica de aproximação entre os sujeitos no cotidiano pedagógico.” (MELO; CRUZ, 2014, p. 31). Durante essa mediação, o professor apresenta, geralmente de forma implícita, as regras de argumentação aos estudantes. Estas regras são conexões lógicas de composição das frases, permitindo identificar se a forma como o pensamento foi expressado é válida ou se apresenta algum tipo de inconsistência, sinalizando possível equivoco na percepção do interlocutor.

O questionário semiestruturado foi aplicado antes e após a Sequência Didática, onde os estudantes responderam questões relativas ao conteúdo trabalhado na mesma, para que então fosse possível perceber as respostas que evidenciassem elementos de desenvolvimento crítico, analítico e científico dos participantes. Houve o cuidado de não interferir nas respostas, por entender que esses momentos da pesquisa são fundamentais para que os dados coletados sejam os mais genuínos possíveis e para não mascarar o processo de análise.

Por fim, a análise do questionário e dos dados a partir da observação da aplicação da Sequência Didática sobre a Educação Ambiental ocorreu por meio da análise qualitativa das inferências dos dados na perspectiva da Análise de Conteúdo que segundo Bardin, a produção de inferências em análise de conteúdo significa não somente produzir suposições subliminares acerca de determinada mensagem, mas em embasá-las com pressupostos teóricos de diversas concepções de mundo e com as situações concretas de seus produtores ou receptores. Assim a análise de conteúdo é "um método empírico que depende do tipo de "fala" a que se dedica e do tipo de interpretação que se pretende como objetivo" (BARDIN, 2011, p. 30). 
A interpretação dos resultados se deu pela descrição das respostas do questionário dos estudantes começando pela leitura dos materiais e agrupando por significações baseado em elementos que apontam o senso analítico. No tratamento dos resultados calcado nos dados brutos, buscou-se torná-los significativos e válidos. Esta interpretação foi além do conteúdo manifesto dos documentos, pois interessa ao pesquisador o conteúdo latente, o sentido que se encontra por trás do imediatamente apreendido.

Assim fecha-se o processo de Análise de Conteúdo, o qual esta centrada na categoria prévia por temática determinada como senso analítico, embasado a luz da literatura científica exposta por Zoller (1993); Mortimer e Santos (2001); Amaral (2006) e Marques (2018).

\section{Resultados e Discussão}

O desenvolvimento do senso analítico foi analisado partindo das premissas respaldas por Zoller (1993), apontado por Mortimer e Santos (2001), Amaral (2006) e Marques (2018) que destacam algumas características para emergir o senso analítico e a capacidade em analisar e emitir pareceres sobre determinando tema. Essas características do desenvolvimento analítico dos participantes podem ser observadas nas respostas relacionadas às questões do Questionário Inicial e Questionário Final como mostra a Tabela 1.

Tabela 1: Desenvolvimento do senso analítico dos estudantes.

\begin{tabular}{|c|c|c|c|}
\hline Categoria & Subcategorias & Componentes & Exemplos de respostas \\
\hline \multirow{7}{*}{$\begin{array}{c}\text { Senso } \\
\text { analítico }\end{array}$} & \multirow[b]{2}{*}{$\begin{array}{l}\text { Geração de novas } \\
\text { opções; visão global. }\end{array}$} & \multirow{2}{*}{$\begin{array}{l}\text { Atividades e } \\
\text { temas } \\
\text { relacionados á } \\
\text { Educação } \\
\text { Ambiental na } \\
\text { escola. }\end{array}$} & $\begin{array}{l}\text { Q.I - } 9 \text { relacionadas ao lixo } \\
\text { - } 1 \text { cuidado com natureza e flores } \\
\text { - } 10 \text { não responderam }\end{array}$ \\
\hline & & & $\begin{array}{l}\text { Q.F - } 11 \text { relacionadas ao lixo } \\
\text { - } 1 \text { Desmatamento } \\
\text { - } 1 \text { Cuidar e Proteger a natureza } \\
\text { - } 1 \text { Respeitar o Meio Ambiente } \\
\text { - } 1 \text { Pegada Ecológica } \\
\text { - } 1 \text { Poluição } \\
\end{array}$ \\
\hline & \multirow{5}{*}{$\begin{array}{l}\text { Reconhecimento da } \\
\text { existência de um } \\
\text { problema; } \\
\text { Tomada de } \\
\text { responsabilidade; } \\
\text { Lidar com } \\
\text { ambiguidades, } \\
\text { conflitos e dados, } \\
\text { Visão de futuro. }\end{array}$} & \multirow{2}{*}{$\begin{array}{l}\text { O que você } \\
\text { entende por } \\
\text { Educação } \\
\text { Ambiental? (Q.I) }\end{array}$} & $\begin{array}{l}\text { A19-“Cuidar do nosso meio ambiente, sem poluir, } \\
\text { reciclando, mas infelizmente muitas pessoas não nos } \\
\text { ajudam". }\end{array}$ \\
\hline & & & $\begin{array}{l}\text { A18-“Não jogar lixos nas ruas, não destruir meio } \\
\text { ambiente, assim você estará fazendo sua parte e também } \\
\text { ter uma cidade limpa e bem cuidada". }\end{array}$ \\
\hline & & \multirow{3}{*}{$\begin{array}{l}\text { O que você acha } \\
\text { de aprender } \\
\text { Educação } \\
\text { Ambiental na } \\
\text { escola? (Q.F) }\end{array}$} & $\begin{array}{l}\text { A02-“Importante para as crianças aprenderem desde cedo } \\
\text { a não fazer o que os adultos fizeram. Jogar lixo nas ruas e } \\
\text { jogar lixo no lugar errado". }\end{array}$ \\
\hline & & & $\begin{array}{l}\text { A05-"Bom, pois assim as próximas gerações podem } \\
\text { ajudar a cuidar do meio ambiente". }\end{array}$ \\
\hline & & & $\begin{array}{l}\text { A10-"Sim porque as crianças tem que saber o que está } \\
\text { acontecendo com o nosso planeta". }\end{array}$ \\
\hline
\end{tabular}


RELACult - Revista Latino-Americana de Estudos em Cultura e Sociedade

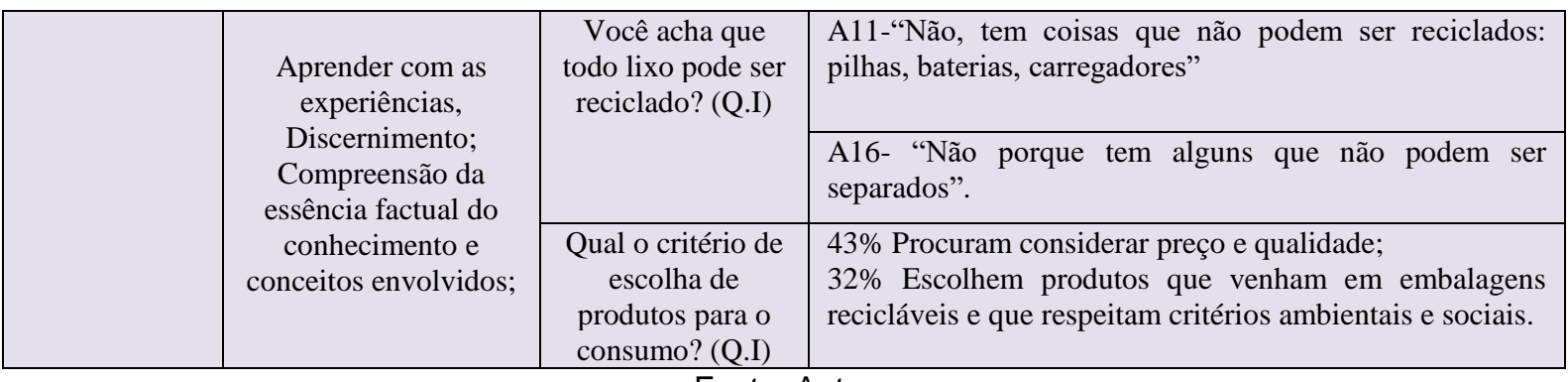

Fonte: Autor

Observa-se que os alunos apresentam elementos que evidenciam o desenvolvimento do senso analítico tais como: reconhecimento da existência de um problema, geração de novas opções, tomada de responsabilidade, lidar com ambiguidades, conflitos e dados, visão de futuro, aprender com as experiências, discernimento, compreensão da essência factual do conhecimento e conceitos envolvidos, análise dos dados pela sua racionalidade ou tomada de decisão, interpretação de dados pela sua intuição, raciocínio lógico, pensamento analítico. No entanto se verificou que a frequência das respostas relacionadas ao senso analítico foram maiores no (Q.I).

Por meio das respostas dos estudantes na Tabela 01 é possível fazer um comparativo fazendo ligação entre o antes e o depois da aplicação da Sequência Didática ampliando seus conceitos e ainda gerando novas opções para demonstrar sua compreensão sobre a temática estudada. Esse fato se destaca pela relevância de reconhecer a existência de um problema ou outros problemas que não tinha clareza para se expressar.

Demonstram-se pelos dados que os estudantes afloram pela tomada de responsabilidade e permite ainda uma análise de como lidar com ambiguidade, conflitos, dados, além de conceber uma perspectiva de visão de futuro que assomam aos dados que tinham anteriormente, tornando sua visão global, além da extração de informações relevantes obtidas da sua relação e compreensão do assunto desvelado que se concretiza com seu posicionamento frente à problemática ambiental.

O posicionamento é uma das características para tomada de decisão, fator intrínseco no senso analítico; percebe-se a partir das respostas dos estudantes a sua aptidão para aprender com as experiências e incrementar o discernimento demonstrando a compreensão da essência factual dos conhecimentos e conceitos envolvidos. É por meio desta congruência e coesão que se destaca a racionalidade demonstrada em forma de exemplos dados pela sua interpretação ou raciocínio tornando parte do seu pensamento. 


\section{Considerações Finais}

Os resultados demonstram que a Educação Ambiental no currículo escolar pode auxiliar na plenitude da formação educativa transformadora e emancipatória. Sendo assim é importante e fundamental que cada estudante desenvolva as suas potencialidades e adote posturas pessoais, comportamentais e socialmente construídas, colaborando para a construção de uma sociedade igualitária e ambientalmente justa, em um ambiente saudável.

É necessário que a escola não seja mais vista como um simples espaço de transmissão de conceitos, mas sim como um lugar de construção de conhecimentos para que o processo de ensino-aprendizagem tenha sentido. A Educação Ambiental no processo de ensino e aprendizagem é hoje o instrumento eficaz para se compreender a interação entre o homem e a natureza. É o caminho para que cada indivíduo assuma suas responsabilidades em busca de uma melhor qualidade de vida e redução dos impactos ambientais.

Das inferências enunciadas pode-se concluir que o desenvolvimento do senso analítico se evidencia elementos como a capacidade analítica, a argumentação dos estudantes é constituindo como um objetivo pedagógico fundamental, e em consequência as formas de elaboração de argumentos substantivos um conteúdo a ensinar e a aprender nas nossas escolas. Destaca-se ainda a compreensão sobre suas decisões de consumo e a geração de novas opções trazendo a responsabilidade do cuidado ambiental e da não geração de resíduos.

\section{Referências}

AMARAL, R. M. Desenvolvimento e aplicação de um método para o mapeamento de competências em inteligência competitiva. 2006. 209 f. Dissertação (Mestrado em Engenharia de Produção)- Universidade Federal de São Carlos, São Carlos, 2006. Disponível em: <http:// bdtd.ufscar.br>. Acesso em: 10/01/2019.

AMERICAN PSYCHOLOGICAL ASSOCIATION. Dicionário de Psicologia - APA. Porto Alegre: Artmed, 2010.

BANERJEE, A.; BANDYOPADHYAY, T.; ACHARYA, P. Data analytics: Hyped up aspirations or true potential. Vikalpa, v. 38, n. 4, p. 1-11, 2013.

BAGGINI, J.; FOSL, P. S. As ferramentas dos filósofos: um compendio sobre conceitos e métodos filosóficos. São Paulo: Loyola, 2008.

BARDIN, L. Análise de Conteúdo (Edição revista e actualizada). Lisboa: Edições, v. 70, 2009. 
BECK, J. B. and WIERSEMA, M. F. 'Executive Decision Making: Linking Dynamic Managerial Capabilities to the Resource Portfolio and Strategic Outcomes', Journal of Leadership \& Organizational Studies, 20(4), p. 408-419, 2013.

BRAGA, A. A Gestão da Informação. Revista Millenium. v. 19, 2000.

BRASIL. Ministério da Educação e do Desporto. Conselho Nacional de Educação. Câmara de Educação Básica. Parecer CEB n. 4/98. Diretrizes Curriculares Nacionais para o Ensino Fundamental. Brasília, DF: MEC/CNE, 1998.

CARVALHO, I. C. M. Educação ambiental: a formação do sujeito ecológico. 2.ed. São Paulo: Cortez, 2006.

CHALITA, Gabriel. Educação: a solução está no afeto. São Paulo: Gente, 2002.

COMUZZI, M; PATEL, A. How organisations leverage Big Data: a maturity model. Industrial Management \& Data Systems, v. 116, n. 8, p. 1468-1492, 2016.

CRESWELL, J. W.; CLARK, V. L. P. Pesquisa de Métodos Mistos: Série Métodos de Pesquisa. Penso Editora, 2015.

DANKE, I. R. O processo do conhecimento na pedagogia da libertação: as idéias de Freire, Fiori e Dussel. Rio de Janeiro: Vozes, 1995.

EGGERS, J. P.; KAPLAN, S. Cognition and capabilities: a multi-level perspective. The Academy of Management Annals, v. 7, n. 1, p. 295-340, 2013.

ESTEBAN, M. P. S. Pesquisa qualitativa em educação: fundamentos e tradições. Porto Alegre: Artmed, 2010.

EVANS, J. R.; LINDNER, C. H. Business analytics: the next frontier for decision sciences. Decision Line, v. 43, n. 2, p. 4-6, 2012.

FREITAS, L.; MORIN, E.; NICOLESCU, B. Carta de transdisciplinaridade. In: NICOLESCU, B. et al. Educação e transdisciplinaridade. Brasília: UNESCO, p.177-81, 2000.

GAVETTI, G. PERSPECTIVE-Toward a behavioral theory of strategy. Organization Science, v. 23, n. 1, p. 267-285, 2012.

GUEDES, J. C. S. Educação ambiental nas escolas de ensino fundamental: estudo de caso. Garanhuns: Ed. do autor, 2006.

GUIMARÃES, M. A dimensão ambiental na educação. 5. ed. Campinas: Papirus, 1995.

HELFAT, C. E.; MARTIN, J. A. Dynamic Managerial Capabilities Review and Assessment of Managerial Impact on Strategic Change. Journal of Management, 41(5), 1281-1312. 2015.

HODGKINSON, G. P.; STARBUCK, W. H. Organizational decision making: mapping terrains on different planets. In: The Oxford Handbook of Organizational Decision Making. 2008. 
LAVALLE, S.; LESSER, E.; SHOCKLEY, R.; HOPKINS, M. S.; KRUSCHWITZ, N. Big data, analytics and the path from insights to value. MIT Sloan Management Review, v. 52, n. 2, p. 21, 2011.

MANGUEIRA, L. G.; ALVES, A. S. Análise comparativa dos principais modelos de maturidade destinados à gestão de dados. In: X Congresso Nacional de Excelência em Gestão, Rio de Janeiro, 2014.

MARQUES, R. Pegada ecológica do lixo: desenvolvimento crítico, analítico e científico na educação ambiental de estudantes do $6^{\circ}$ ano do ensino fundamental. 2018. 146 f. Dissertação (Mestrado em Formação Científica, Educacional e Tecnológica) - Universidade Tecnológica Federal do Paraná, Curitiba, 2018. Disponível em: <

http://repositorio.utfpr.edu.br/jspui/handle/1/2964 >. Acesso em: 10/01/2019.

MATIAS, C. J.; GRECO, P. J. Cognição \& ação nos jogos esportivos coletivos. Ciências \& Cognição, v. 15, n. 1, p. 252-271, 2010.

MELO, M. C. H.; CRUZ, G. C. Roda de conversa: uma proposta metodológica para a construção de um espaço de diálogo no ensino médio. Revista Imagens da Educação [on-line] v. 4, n. 2, p. 31-39, 2014 Disponível em: Acesso em: 09/01/2019.

MORTIMER, E.F; SANTOS, W.L.P. Tomada de Decisão para Ação Social Responsável no Ensino de Ciências. Revista Ciência \& Educação, v.7, n.1, p. 95-111, 2001.

NADKARNI, S.; BARR, P. S. Environmental context, managerial cognition, and strategic action: an integrated view. Strategic Management Journal, v. 29, n. 13, p. 1395-1427, 2008.

NICOLESCU, B. A pratica da transdisciplinaridade. In: NICOLESCU, B. et al. Educação e Transdisciplinaridade. Brasília: UNESCO, p. 139-152, 2000.

PEDROSO, C. V. Jogos didáticos no ensino de biologia: uma proposta metodológica baseada em modelo didático. In Anais do IX Congresso Nacional de Educação - Educere; III Encontro Sul Brasileiro de Psicopedagogia - PR (pp. 3182-3190). Curitiba, PR, 2009. Disponível em: < http://pt.calameo.com/read/0051600938835ab1c48ec > Acesso em: 10/01/2019.

PIPINO, L. L.; LEE, Y. W.; WANG, R. Y. Data quality assessment. Communications of the ACM, v. 45, n. 4, p. 211-218, 2002.

SANTOS, E. M.; FARIA, L. C. M. O educador e o olhar antropológico. Fórum Crítico da Educação: Revista do ISEP/Programa de Mestrado em Ciências Pedagógicas. v. 3, n. 1, out. 2004.

SIMON, H. A. Bounded rationality and organizational learning. Organization Science, v. 2, n. 1, p. 125-134, 1991.

TEECE, D. J.; PISANO, G. The dynamic capabilities of firms: an introduction. Industrial and Corporate Change, v. 3, n. 3, p. 537-556, 1994. 
TOULMIN, S. The uses of Argument.New York: Cambridge University Press, 1958.

ZOLLER, U. Expanding the meaning of STS and the movement across the globe. In:

YAGER, R. E. (Ed.). The science, technology, society movement.Washington, DC: National Science Teachers Association, p.125-134, 1993.

WALSH, J. P. Managerial and organizational cognition: Notes from a trip down memory lane. Organization Science, 6: 280-321, 1995.

WENZEL, J. W. Three Perspectives on Argument: Rhetoric, Dialetic, Logic. In: TRAPP, R. e SCHUETZ, J. (Ed.). Perspectives of argumentation: Essays in honour of Wayne Brockriede.

New York: Waveland, p. 9-26, 1990.

YUS, R. Educação integral: uma educação holística para o século XXI. Porto Alegre: Artmed, 2002. 